Case report

\title{
Panhypopituitarism in HIV patient receiving antiretroviral therapy
}

\author{
Tatyana B. Morgunova, Ekaterina S. Maloletkina, Ilya I. Amergulov, Irina V. Glinkina, Maria G. Pavlova, \\ Valentin V. Fadeyev
}

I.M. Sechenov First Moscow State Medical University (Sechenov University), Moscow, Russia

Received 26 September 2020, Revised 15 December 2020, Accepted 24 January 2021

(C) 2020, Russian Open Medical Journal

\begin{abstract}
The article is dedicated to a clinical case of the panhypopituitarism development in a patient with HIV infection receiving antiretroviral therapy. The number of HIV-infected patients worldwide has increased significantly over the past decades. The introduction of highly active antiretroviral therapy into practice has significantly improved the prognosis for these patients. At the same time, the use of this therapy type is associated with a number of complications - in particular, with the development of the immune restoration syndrome. In addition, cases of endocrine dysfunction are described in many publications. Timely diagnosis and treatment of endocrine disorders would help avoiding complications caused by excess or deficiency of hormones.
\end{abstract}

Keywords: panhypopituitarism, HIV infection, highly active antiretroviral therapy.

Cite as Morgunova TB, Maloletkina ES, Amergulov II, Glinkina IV, Pavlova MG, Fadeev VV. X Panhypopituitarism in HIV patient receiving antiretroviral therapy. Russian Open Medical Journal 2021; 10: e0402.

Correspondence to Tatyana B. Morgunova. Address: I.M. Sechenov First Moscow State Medical University (Sechenov University), 8 Trubetskaya St., Bld. 2 , Moscow 119991, Russia. E-mail: morgunova_t_b@staff.sechenov.ru.

\section{Introduction}

The number of patients with acquired immunodeficiency syndrome (AIDS), or those infected with the human immunodeficiency virus (HIV), is growing steadily worldwide, with a total number of cases ca. 38 million in 2019 [1]. Since 1996, highly active antiretroviral therapy (HAART) has been introduced into medical practice, and by 2019 , approximately 25.4 million HIV-infected patients (67\%) were receiving this treatment option. The use of HAART in the treatment of HIV-infected patients has led to a significant improvement in the prognosis for patients, a decrease in the AIDS incidence and increase in life expectancy. At the same time, the prevalence and structure of concomitant pathology changed in these patients. In particular, they often develop endocrine system dysfunctions and autoimmune diseases, which require timely diagnosis and treatment. Analysis of available publications revealed a very few descriptions of pituitary insufficiency cases in such patients. The studies published in 1980s and 1990s described mainly tumors and opportunistic infections (cytomegalovirus, toxoplasmosis, herpes) among the causes of hypopituitarism in patients with HIV infection [2-4]. With the introduction of HAART, the prevalence of opportunistic infections has decreased. As a result, the number of complications has decreased. Among recent publications, cases of pituitary abscess with subsequent development of panhypopituitarism [5], hemorrhage in the pituitary gland against the background of cytomegalovirus infection, and development of panhypopituitarism in patients receiving HAART [6] were described. In this article, we are presenting a clinical observation of panhypopituitarism in a patient with HIV infection receiving HAART.

\section{Case description}

In January 2019, a 58-year-old man, was seen at the Clinic of Endocrinology of the University Clinical Hospital No. 2, I.M. Sechenov First Moscow State Medical University (Sechenov University), with complaints of general weakness, fatigue, poor performance, weight loss and decreased libido.

From the anamnesis:

In 2005, oropharyngeal candidiasis and esophageal candidiasis, along with manifestation of cytomegalovirus infection were diagnosed. The examination has revealed stage $4 \mathrm{C}$ of HIV infection sensu clinical classification adopted in the Russian Federation, AIDS. Antiretroviral therapy was prescribed, and conservative therapy of opportunistic infections was carried out. In 2007, with dynamic monitoring, gastric lymphoma was diagnosed, and six courses of polychemotherapy were carried out. Esophagogastroduodenoscopy performed in 2018 revealed no presence of gastric lymphoma.

Since 2005, the patient has been receiving antiretroviral therapy using various regimens: efavirenz + zidovudine + lamivudine; darunavir + ritonavir + zidovudine + lamivudine; darunavir + ritonavir + abacavir + lamivudine. At the time of the medical appointment in 2019, the patient was taking raltegravir $400 \mathrm{mg}$ (1 pill twice daily); lamivudine $150 \mathrm{mg}$ (1 pill twice daily); abacavir $600 \mathrm{mg}$ (1 pill once a day). Immune status from October 2019 was as follows: CD4=744 (24\%), CD8=1206 (39\%), $\mathrm{CD} 4 / \mathrm{CD} 8=0.62$. The HIV RNA viral load, as of October 2019, was undetectable. There were no opportunistic diseases at the time of appointment in January 2019. 


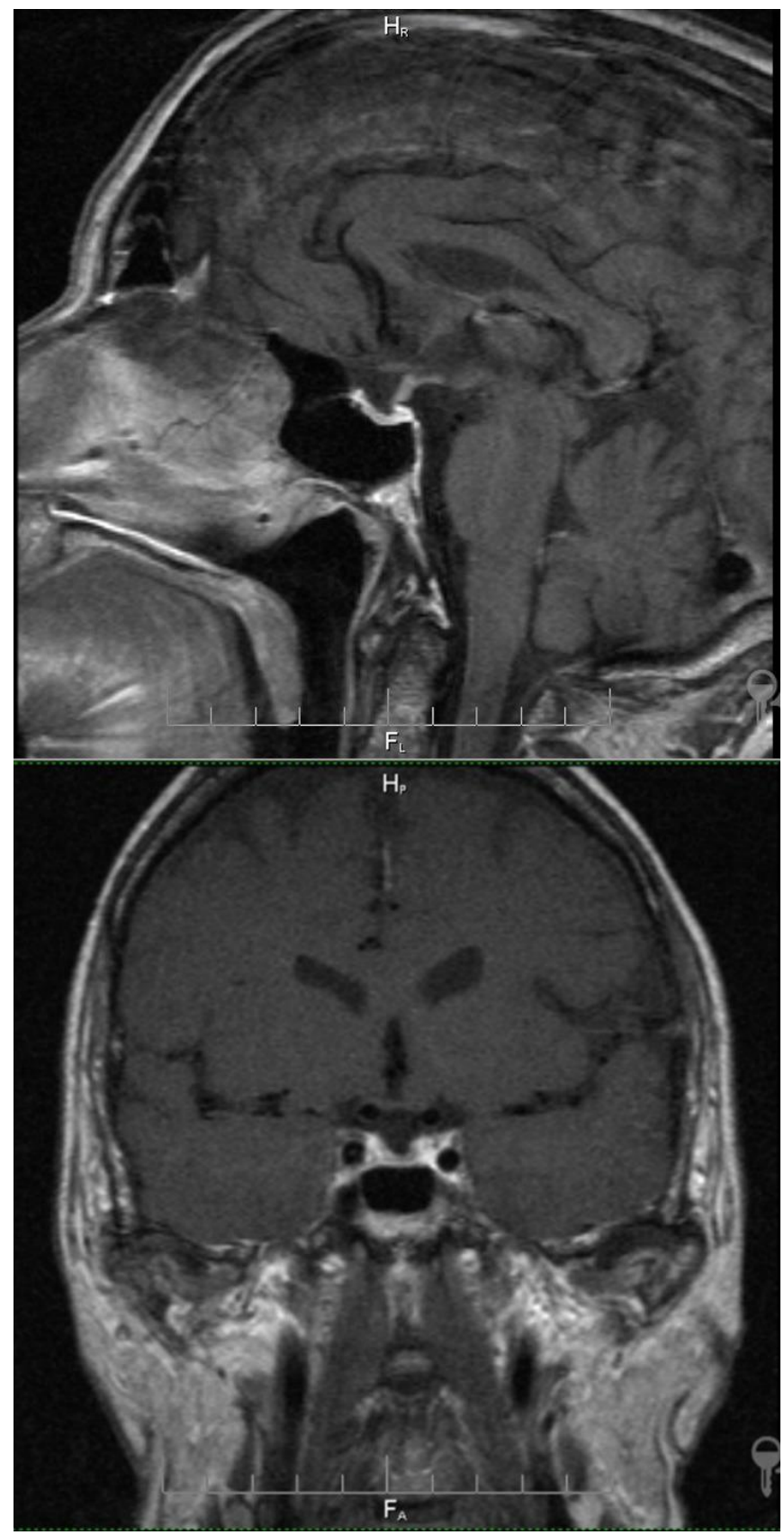

Figure 1. Contrast-enhanced brain MRI (from February 2019).

Complaints of general weakness, fatigue, poor performance, weight loss and decreased libido over 6-7 months (from the summer of 2018), gradually increasing; the reduction in body weight was $17 \mathrm{~kg}$ over the past 1.5 years (from $80 \mathrm{~kg}$ in July 2017 to $63 \mathrm{~kg}$ in January 2019). According to the results of medical investigation in September 2018: $\mathrm{TSH}=0.34 \mu \mathrm{U} / \mathrm{ml}$ (0.4-4.0), free $\mathrm{T} 4=9.75 \mathrm{pmol} / \mathrm{l}$ (12-22). Levothyroxine $50 \mu \mathrm{g} /$ day was prescribed to the patient.

In February 2019, upon admission to the Clinic of Endocrinology: the patient's height was $175 \mathrm{~cm}$, weight was $63 \mathrm{~kg}$, and $\mathrm{BMI}=20.9 \mathrm{~kg} / \mathrm{m}^{2}$. The skin was pale and moderately moist to dry. There was a poor growth of facial hair, and lack of hair growth in the armpits. The subcutaneous fat was moderately developed and evenly distributed. $\mathrm{BP}=85 / 55 \mathrm{~mm} \mathrm{Hg}$ on both arms. Pulse was
78 beats per minute. According to the questionnaire on erectile function (International Index of Erectile Function - IIEF-5), severe erectile dysfunction (ED) was established (5 points). Based on the results of the questionnaire on the symptoms of aging in men the Aging Males Symptoms (AMS) scale, severe androgen deficiency was revealed (62 points).

At the clinic, in February 2019, general and biochemical blood tests were conducted, which revealed the values within the reference ranges (which are indicated in parentheses). Hormonal studies (blood): $\mathrm{TSH}=0.2 \mu \mathrm{lU} / \mathrm{ml}(0.4-4)$; free $\mathrm{T} 4=7.3 \mathrm{pmol} / \mathrm{l}(11.5-$ 23.2); free $\mathrm{T} 3=4.6 \mathrm{pmol} / \mathrm{I}$ (3.5-6.5); $\mathrm{TPOAb}=42 \mathrm{IU} / \mathrm{ml}(0-60)$; cortisol=53 nmol/l (119-618); total testosterone $=2.5 \mathrm{nmol} / \mathrm{l}(8.4-$ 28.7); free testosterone (calculated) $=21.1 \mathrm{pmol} / \mathrm{l} ; \mathrm{SHBG}=73 \mathrm{nmol} / \mathrm{l}$ (10-57); $\mathrm{FSH}=2.6 \mathrm{mIU} / \mathrm{ml}$ (1.4-18.1); $\mathrm{LH}=0.9 \mathrm{mIU} / \mathrm{ml}$ (1.5-9.3); prolactin $=433 \mu \mathrm{lU} / \mathrm{ml}(45-375) ;$ ACTH=8.2 pmol/l (0-10.2).

A test with insulin hypoglycemia was performed. Secondary adrenal insufficiency and somatotropic insufficiency were diagnosed. Hypoglycemia was achieved at the 30th minute (blood glucose $1.8 \mathrm{mmol} / \mathrm{l})$. The maximum level of growth hormone in hypoglycemia was detected at the 60th minute of the test $1<0.066$ $\mathrm{ng} / \mathrm{ml})$. The maximum level of cortisol was identified at the 60th minute of the test (30 minutes after hypoglycemia) $(89 \mathrm{nmol} / \mathrm{l})$. Hydrocortisone was prescribed at a daily dosage of $15 \mathrm{mg}$, divided into two doses (10 $\mathrm{mg}$ at 8:00 hr and $5 \mathrm{mg}$ at 15:00 hr). Against this background, the patient noted an improvement in overall health: a decrease in weakness and fatigue, along with a weight gain of $5 \mathrm{~kg}$. From September 2019 through February 2020, the daily dose of hydrocortisone was $10 \mathrm{mg}: 5 \mathrm{mg}$ at 8:00 hr and $5 \mathrm{mg}$ at 13:00 hr. Against the background of replacement therapy for secondary hypothyroidism with levothyroxine in a daily dose of 50 $\mu \mathrm{g}$, the level of free T4 remained low $(7.3 \mathrm{pmol} / \mathrm{l})$ : hence, from February 2019, the dose of levothyroxine was increased to $125 \mu \mathrm{g}$ per day.

Also, from the results of conducted analyses, we diagnosed secondary hypogonadism (total testosterone $=2.5 \mathrm{nmol} / \mathrm{l}, \mathrm{LH}=0.9$ $\mathrm{mIU} / \mathrm{ml}$ ). Since November 2019, the patient has been receiving testosterone in the form of a gel: $50 \mathrm{mg}$ transdermally onto the abdomen. Against this background, the patient noted a decrease in weakness and fatigue, amplified libido, and an increase in the number of erections. According to the data from December 2, 2020: total testosterone $=13.27 \mathrm{nmol} / \mathrm{I}(\mathrm{N} 8.4-28.7)$; total $P S A=0.65$ $\mathrm{ng} / \mathrm{ml}$ (N 0.001-4.0); AST=27 U/I (N 0.1-40); ALT=20 U/I (N 5-41).

From X-ray absorption densitometry on February 21, 2019, we detected osteopenia in L3 (T-score: -1.0 SD) and in the proximal left thigh (T-score: $-1.1 \mathrm{SD}$ ).

Thus, the patient was diagnosed with panhypopituitarism. To clarify the etiology of panhypopituitarism, magnetic resonance imaging of the chiasmatic and sellar regions was performed in February 2019: the suprasellar cistern prolapsed into the cavity of the sella turcica. The pituitary gland was flattened and had the following dimensions: vertical $=2.5 \mathrm{~mm}$, transverse $=14 \mathrm{~mm}$, anteroposterior $=14 \mathrm{~mm}$. The structure of the adenohypophysis was heterogeneous; with contrast enhancement, no zones of pathological accumulation of the contrast agent were detected. The pituitary stalk thickened to $4 \mathrm{~mm}$, while its normal thickness should not exceed $2 \mathrm{~mm}$. Thus, the medical report stated MR image of a partially empty sella turcica. Hence, the patient was offered re-hospitalization at the Clinic of Endocrinology in February 2020. 
Results of physical, laboratory and instrumental examination (February 2020)

\section{Physical examination data}

The patient's height $=175 \mathrm{~cm}$, weight $=75 \mathrm{~kg}, \mathrm{BMI}=24.49 \mathrm{~kg} / \mathrm{m}^{2}$. Body temperature was $36.6^{\circ} \mathrm{C}$, and skin was moderately moist and normally colored. The subcutaneous fat was moderately developed and evenly distributed. There was swelling and tenderness on palpation laterally to the right nipple, but no edema. In the patient, we detected vesicular breathing, no wheezing, respiratory rate of 16 per minute, muffled and rhythmic heart sounds, $\mathrm{BP}=110 / 80 \mathrm{~mm} \mathrm{Hg}$ on both arms. The pulse was 72 per minute, rhythmic. Peripheral vascular pulsation was maintained. On palpation, the abdomen was soft, painless in all parts. Liver was located along the midclavicular line and the edge of the costal arch. The symptom of tapping in the lumbar region was negative on both sides. The thyroid was not enlarged (as identified by palpation), painless, nodular formations were not palpable.

\section{Laboratory results}

Complete blood count, biochemical blood test: no clinically significant abnormalities were detected.

Lipid spectrum: Cholesterol: $4.26 \mathrm{mmol} / \mathrm{l}(\mathrm{N}<4.5)$; triglycerides: $1.08 \mathrm{mmol} / \mathrm{l}(\mathrm{N}<1.7) ; \mathrm{LDL}: 2.56 \mathrm{mmol} / \mathrm{l}(\mathrm{N}<2.5) ; \mathrm{HDL}: 1.21 \mathrm{mmol} / \mathrm{I}$ (N>1.0); VLDL: $0.49 \mathrm{mmol} / \mathrm{l}$ (N 0.19-0.77); AC (calculated): 2.52 (N 2.2-3.5).

Hormone studies (blood serum): Table 1.

Clinical urine tests: pH: 5 (N 5.0-7.0); specific gravity: $1025 \mathrm{~g} / \mathrm{l}$ (N 1005-1034); urine sediment: no specific features.

\section{Contrast-enhanced pituitary MRI}

The pituitary tissue lined the bottom of the sella turcica with a thin layer. The dimensions: anteroposterior $=14 \mathrm{~mm}$, bilateral $=11$ $\mathrm{mm}$, vertical=up to $3 \mathrm{~mm}$. Emerging empty sella turcica was detected. The pituitary gland was homogeneous, its upper surface was concave, the stalk was not deflected, the optic chiasm was not compressed, and the suprasellar cistern was not dilated. The cavernous sinus and visible parts of the internal carotid artery and carotid siphon were without pathological changes. With the bolus injection of a contrast agent (Magnevist ${ }^{\circledR}: 0.2 \mathrm{ml} / \mathrm{kg}$ of the body weight), its uniform accumulation by the pituitary tissue was noted. No areas of the contrast agent pathological accumulation were found in the brain. Thus, the medical report stated the MR image of emerging empty sella turcica, while no MR signs of pituitary neoplasms were detected in the study with contrast enhancement (Figure 1).

\section{Outcome and results of the follow-up monitoring}

Based on the existing complaints and the examination conducted in February 2019, a patient at the stage 4C of HIV infection, AIDS, in remission while receiving antiretroviral therapy, was diagnosed with panhypopituitarism. The duration of HAART at the time of panhypopituitarism diagnosis was 15 years. The patient was prescribed replacement therapy for secondary adrenal insufficiency, secondary hypothyroidism and hypogonadism. Against the background of the ongoing therapy from February 2019 to February 2020, the patient's performance improved significantly: weakness and fatigue decreased, and he gained weight of $12 \mathrm{~kg}$. In February 2020, based on the results of the second medical examination, the correction of the ongoing substitution therapy was carried out.

A repeated MRI study of the pituitary gland with contrast enhancement was carried out; and the presence of a developing empty sella turcica was confirmed. Given the patient's HIV infection, the clinic continued antiretroviral therapy, and the supervision by an infectious disease specialist was recommended.

\section{Discussion}

In presented clinical case, the patient, at the time of the visit to the clinic, in February 2019, had a definitive clinical picture of panhypopituitarism. An interesting fact is that panhypopituitarism has developed 15 years after the detection of HIV infection, AIDS, and initiation of HAART.

In this patient, the deficiency of tropic hormones arose due to emerging empty sella syndrome (ESS). ESS often causes the loss of one or more tropic functions of the pituitary gland. Technically, ESS presumes that the cerebrospinal fluid fills over $50 \%$ of the sella turcica volume, or else the pituitary gland is less than $3 \mathrm{~mm}$ thick; whereas the scenario, in which the fluid fills less than $50 \%$ of the volume, is called the partially empty sella syndrome $[7,8]$. According to a systematic review by Matthias K. Auer et al. [8], the prevalence of hypopituitarism in patients with EES ranges from 15 to $68 \%$. Obviously, the loss of tropic functions develops more often with the full variant of the syndrome than with the partial syndrome [9].

The cause of EES formation in our patient is not entirely clear. It is well-known that there are two variants of this syndrome. The first one is called the primary EES, occurring when there was no previous pathological process in the pituitary region [7]. Primary EES can be detected incidentally via MRI, as well as during examination for headaches, neurological or visual impairments, or signs of pituitary insufficiency. The second variant is called secondary EES. It is formed as a result of a surgical or radiology treatment of the pituitary adenoma, or after its spontaneous regression. Secondary EES is more often formed in patients with obesity and/or arterial hypertension; in women, especially in the presence of several pregnancies in anamnesis, as well as after suffering from hypophysitis (especially, its lymphocytic type). Our patient had no history of any factors contributing to the formation of EES (obesity, arterial hypertension). Initially, according to MRI performed in 2019, he had a thickening of the pituitary stalk, which may serve as an indirect sign of hypophysitis. At the same time, the hypophysitis is also characterized by an increase in the volume of the pituitary gland, which was not the case in this patient [10].

We did not have an opportunity to detect anti-pituitary antibodies that could confirm or exclude the presence of lymphocytic hypophysitis.

Table 1. Hormone studies (blood serum)

\begin{tabular}{lll}
\hline Hormone & Result & Reference range \\
\hline Free T4, pmol/l & 18.9 & $11.5-23.2$ \\
Total testosterone, nmol/l & 3.7 & $8.4-28.7$ \\
SHBG, nmol/l & 60 & $10-57$ \\
Free testosterone (calculated), pmol/l & 46 & \\
Prolactin, $\mathrm{mlU} / \mathrm{ml}$ & 386 & $45-375$ \\
\hline
\end{tabular}




\section{Conclusion}

The presented case is interesting from a clinical standpoint. The first symptoms of tropic hormones deficiency of the pituitary gland in a patient appeared approximately six months before the diagnosis, and they gradually increased since then. Naturally, secondary adrenal insufficiency was the main factor determining the severity of the patient condition at the time of pituitary insufficiency detection. The potential impact of a stress factor (infection, trauma, surgery) could lead to severe decompensation of adrenal insufficiency and an aggravation of the patient condition. The timely diagnosis of panhypopituitarism, along with the prescription of replacement therapy have led to an improvement in the patient well-being and an increase in his performance and quality of life. Further on, he would need a lifelong substitution therapy, dose adjustment of medications, and supervision of an endocrinologist.

\section{Funding}

No external sources of funding for this study are acknowledged.

\section{Written informed consent}

The patient voluntarily signed the informed consent form for the publication of anonymized personal medical information.

\section{Conflict of interest}

The authors declare no obvious or potential conflicts of interest related to the publication of this article.

\section{Authors' contributions}

All authors made a significant contribution to the preparation of the manuscript, read and approved the final draft prior to its publication.

\section{References}

1. The Global HIV/AIDS Epidemic. 2021. https://www.hiv.gov/hivbasics/overview/data-and-trends/global-statistics.

2. Sullivan WM, Kelley GG, O'Connor PG, Dickey PS, Kim JH, Robbins R, et al. Hypopituitarism associated with a hypothalamic CMV infection in a patient with AIDS. Am J Med 1992; 92(2): 221-223. https://doi.org/10.1016/0002-9343(92)90119-v.

3. Madhoun ZT, DuBois DB, Rosenthal J, Findlay JC, Aron DC. Central diabetes insipidus: a complication of herpes simplex type 2 encephalitis in a patient with AIDS. Am J Med 1991; 90: 658-659. https://pubmed.ncbi.nlm.nih.gov/2029028/.

4. Milligan SA, Katz MS, Craven PC, Strandberg DA, Russell IJ, Becker RA. Toxoplasmosis presenting as panhypopituitarism in a patient with the acquired immune deficiency syndrome. Am J Med.1984; 77(4): 760764. https://doi.org/10.1016/0002-9343(84)90381-4.

5. Yamazaki H., Kobayashi M., Sarca A., Takaori-Kondo A. Pituitary abscess in an HIV-1-infected patient. SAGE Open Med Case Rep 2017; 5: 2050313X17701374. https://doi.org/10.1177/2050313×17701374.

6. Wong $\mathrm{N}$, Levy $\mathrm{M}$, Stephenson I. Hypogonadism in the HIV-Infected Man. Curr Treat Options Infect Dis 2017; 9(1): 104-116. https://doi.org/10.1007/s40506-017-0110-3.

7. Guitelman $M$, Basavilbaso Natalia $G$, Vitale $M$, Chervin $A$, Katz $D$, Miragaya K, et al. Primary empty sella (PES): a review of 175 cases. Pituitary 2013; 16(2): 270-274. https://doi.org/10.1007/s11102-0120416-6.

8. Auer MK, Stieg MR, Crispin A, Sievers C, Stalla GK, Kopczak A. Primary empty sella syndrome and the prevalence of hormonal dysregulation. Dtsch Arztebl Int 2018; 115(7): 99-105. https://doi.org/10.3238/arztebl.2018.0099.
9. Zuhur SS, Kuzu I, Ozturk FY, Uysal E, Altuntas Y. Anterior pituitary hormone deficiency in subjects with total and partial primary empty sella: do all cases need endocrinological evaluation? Turk Neurosurg 2014; 24: 374-379. https://doi.org/10.5137/1019-5149.jtn.8671-13.0.

10. Angelousi A, Cohen C, Sosa S, Danilowicz K, Papanastasiou L, Tsoli M, et al. Clinical, Endocrine and imaging characteristics of patients with primary hypophysitis. Horm Metab Res 2018; 50(4): 296-302. https://doi.org/10.1055/s-0044-101036.

\section{Authors:}

Tatyana B. Morgunova - MD, PhD, Associate Professor, Department of Endocrinology No. 1, N.V. Sklifosovsky Institute of Clinical Medicine, I.M. Sechenov First Moscow State Medical University (Sechenov University), Moscow, Russia. http://orcid.org/0000-0003-1500-1586.

Ekaterina S. Maloletkina - MD, Endocrinologist, Therapeutic Department of Endocrinology No. 2, University Clinical Hospital No. 2, I.M. Sechenov First Moscow State Medical University (Sechenov University), Moscow, Russian. https://orcid.org/0000-0001-9881-5459.

Ilya I. Amergulov - Clinical Resident, Department of Endocrinology No. 1, N.V. Sklifosovsky Institute of Clinical Medicine, I.M. Sechenov First Moscow State Medical University (Sechenov University), Moscow, Russia. https://orcid.org/0000-0001-8637-1483.

Irina V. Glinkina - MD, PhD, endocrinologist, Associate Professor Department of Endocrinology No. 1, N.V. Sklifosovsky Institute of Clinica Medicine, I.M. Sechenov First Moscow State Medical University (Sechenov University), Moscow, Russia. http://orcid.org/0000-0001-8505-5526.

Maria G. Pavlova - MD, PhD, Endocrinologist, Associate Professor, Department of Endocrinology No. 1, N.V. Sklifosovsky Institute of Clinica Medicine, I.M. Sechenov First Moscow State Medical University (Sechenov University), Moscow, Russia. https://orcid.org/0000-0001-6073-328X.

Valentin V. Fadeyev - MD, DSc, Professor, Corresponding Member of the Russian Academy of Sciences, Chair of the Department of Endocrinology No. 1, N.V. Sklifosovsky Institute of Clinical Medicine, I.M. Sechenov First Moscow State Medical University (Sechenov University), Moscow, Russia. http://orcid.org/0000-0002-3026-6315. 